\title{
AYURVEDIC RESEARCH IN INDIA: TRADITION AND MODERNITY \\ A PROFILE OF THE WORK OF DR NARENDRA BHATT
}

Dr Narendra S. Bhatt, MD Ayu, BSc, practising physician representing the fourth generation of ayurvedic practice, has received four national awards to honour his work as an ayurvedic scholar and clinician, and in 2006 he was awarded the IASTAM Basham Medal in acknowledgment of his clinical excellence and longstanding service to the association at both national and international level. Right from its inception in 1980, Dr Bhatt has played a significant administrative and inspirational role for the Indian chapter of IASTAM, which celebrated its silver jubilee in 2005 . He has more than 55 scientific articles and a jointly held patent to his credit and 32 years of teaching, clinical, research and pharmaceutical experience. He has contributed towards new methods and models that facilitate an integrated approach to ayurved and biomedicine. Dr Bhatt has been nominated to several governmental committees and bodies, including the Ayurvedic Pharmacopoeia Committee and the Bioresource Development Board, and has represented ayurveda on several international delegations on behalf of the Ministry of Health, Government of India. He is a member of the core group for a project on Indigenous Knowledge for Health under Global Research Alliance, to be funded by the World Bank and has been Chief Executive Officer of Zandu Pharma, one of the largest ayurvedic manufacturing companies in India. Dr Bhatt has been on the Governing Council and on Scientific Advisory Committee of Central Council for Research in Ayurved and Siddha, the prime research body under Ministry of Health. He was also a member of the Board of Studies of Faculty of Ayurveda in Mumbai, and other universities and continues to be associated with academic activities. He has been a referee and examiner for the postgraduate Ayurvedic and Pharma examinations at several universities. He is currently vice-president of the Ayurvedic Drug Manufacturers' Association and has successfully organised several important national and international conferences and meetings. Dr Bhatt has travelled extensively in both India and abroad during the last 20 years and 
given more than 50 seminars and talks in European and other countries on subjects related to ayurved.

\section{What made you choose a career as an ayurvedic practitioner?}

Right from my childhood, I was interested in medicine as a career, though I was not sure whether to choose modern biomedicine or ayurved. However, having been born into a family of ayurvedic practitioners going back three generations, it seemed more natural to continue the line into the fourth generation. My father's dispensary was located in the same building as our family residence; I was therefore exposed to ayurvedic practice from an early age and had many opportunities to observe my father's methods of diagnosis and treatment, and even the preparation of medicines. Because of my father's involvement in socio-political activities and campaigns, as a proponent of 'shuddha (puritan) ayurved', I was also exposed to the struggle for the survival of ayurved during the late 1950s and 1960s, until the Central Council of Indian Medicine was eventually established in 1971. The office of the Mumbai Vaidya Sabha (Association of Ayurvedic Physicians of Mumbai), one of the oldest organisations of ayurvedic physicians in the country, operated from my father's dispensary until 1974. I remember observing their meetings and their deliberations as a child and teenager. Later my father edited a centuryold history of the Mumbai Vaidya Sabha. However, I was even more inspired by the stories about my grandfather, an ayurvedic physician and astrologer, who had taken 'sanyas' (renouncing worldly bounds) ten years before my birth. His writings consisted of several volumes; were kept at my native home, together with pharmacy products and some clinical equipment.

\section{Where did you receive your training and how do you think this affected the way you do your clinical work?}

I was educated at one of the Ayurvedic Colleges in Mumbai. I received my main clinical training after graduation in a Government Hospital under Vaidya D. S. Antarkar, a well-known clinician and researcher, and later, when I was a junior teacher in the clinical 
subject of Kayachikitsa (internal medicine), under Vaidya Vasudev Shastri Lata, a scholar with many years of experience.

I also looked for every opportunity to meet, observe and discuss with learned experts, such as Kaviraj Krishna Chandra Punjabi and Vaidya Shriram Sharma in Mumbai and academics and expert clinicians from other parts of the country like Professor C. P. Shukla (Jamnagar), Professor P. J. Deshpande (Banaras) and Vaidya B. P. Nanal (Pune).

While at the Podar Government Hospital and College, I was introduced to research, which taught me to aspire for objectivity in clinical medicine. Being Honorary Adviser at that time with Zandu (Pharmaceutical Works), I used to travel in different parts of the country to initiate and monitor clinical research on pharmaceutical products. I have coordinated nearly 50 clinical studies, both at ayurvedic and allopathic medical institutes.

A total experience of more than 11 years within academic hospital setups gave me a reasonably wide clinical experience, with about 28 to 30 indoor patients to be watched and treated daily, and about 100 to 160 patients every week in outdoor departments affiliated to these hospitals.

Fortunately, I was also exposed to medical social sciences and anthropology during the early part of my career. This broadened my views about health care delivery issues, the methodology involved in the assessment of medical systems and the importance of comparative studies of medical systems and traditions. This helped me to be more analytical and to better understand the doctor-patient relationship.

\section{How did you get involved in IASTAM?}

After the first International Congress of Traditional Asian Medicine (ICTAM) in Australia, there was some interest among delegates from India to create a platform for Asian medical systems, including ayurved. The late Pandit Shiv Sharma, Dr K. N. Udupa and Dr K. M. Parikh were keen to start the Indian chapter of IASTAM. While still a teacher at Ayurvedic College, I had just joined Zandu as Honorary Adviser. On Dr Parikh's suggestion, I took up the membership drive to initiate the Indian chapter in the presence of Professor A. L. Basham in 1980. I got fully involved in its activities thereafter and the rest, as they say, is history. 


\section{What are the major future challenges for IASTAM India and IASTAM International?}

Continued interest in any association is dependent on the information provided in areas of interest, services offered, and benefits for interaction and professional development. India has medical pluralism inscribed into its official structure of medical services. Amongst the non-conventional medical traditions, we have ayurved, unani, siddha and homoeopathy, as well as yoga. However, interest in the various branches of Asian medicine by Indian scholars of medical anthropology, medical sociology, philology and similar disciplines is negligible. Also the lack of interest in traditional medical systems (TMS) on the part of biomedical practitioners and researchers is disconcerting. Satisfying the multiple needs in a pluralistic and complex situation constitutes a challenge. IASTAM has tried to meet this challenge by focusing on activities related to the traditional systems.

$\mathrm{We}$, in India, will have to be more active and visible in relation to 'interdisciplinary' approaches. Instead of playing only a catalytic role, perhaps IASTAM India has to become more active in spreading the interdisciplinary agenda, and practitioners may need to be more intent on establishing a dialogue with academics of different disciplines. It is now time for TMS institutes to become more attuned to inter-disciplinary collaboration and exchange. IASTAM India can also play an important role in facilitating the establishment of other regional chapters and in shaping the relationship between the regional chapters and IASTAM International.

The Indian chapter has recently been involved in a proposal to survey and categorise AYUSH institutes (Department of Ayurveda, Yoga, Unani, Siddha and Homoeopathy), which may well lead to a major project with the Ministry of Health in India. Initiatives such as this give regional IASTAM chapters a greater involvement in the way government policies concerning traditional medical systems are shaped to provide bridges where needed.

IASTAM at international level has to work further to establish better links, not only with practitioners but also with academics from the various regions in Asia. There is also a need to extend the role of TSMs in health care delivery in the various regions; this is an important challenge, not least due to the high cost of health care the world over. IASTAM can provide an excellent platform for debate between concerned experts and even work on evolving modalities for the same. 


\section{Where would you like IASTAM to go in the next decade?}

I would like to see IASTAM develop into an internationally recognised interdisciplinary body with a network of regional chapters and quality resources in terms of skills and expertise. It should have an academic but also applied approach to uplift the interests in these systems.

\section{What is the role of research into traditional medical systems in our modern world?}

Tradition is acquired by habit, culture and inheritance. Modernity is concerned essentially with emerging from traditional ways of thinking and adapting to a newer way. Research is a process of inquiry for details. It is in part like rediscovering or re-looking at an existing set of information with a view to assessing it from a new perspective. Research may have its origin in the context of science and may be historically only a few hundred years old, but rediscovering an existing phenomenon and processes to develop newer understandings or applications are part of any knowledge system.

Ayurved is one of the most ancient surviving systematic knowledge bases and had its share of modifications, additions of newer applications, deletions and even permanent losses. Research into it seeks to strengthen its foundations with a view to improving its practical applications. Therefore, research is an important tool for the advance of the art and science of ayurved in many ways. It gives impetus for external and internal development. Research can also function as a good benchmark or marker of validity, depending on its scope, quality, acceptability, applicability and developmental support.

Efforts have been made to interpret ayurvedic principles in order to develop newer applications. This has been part of a longer global culture of research into many traditional medical systems, focusing especially on their pharmacopoeias. A review of research in the last few decades reveals that much has been done. Yet, with some exceptions, not much of this has made its way into ayurvedic practices or ideas.

For example, consider Panax ginseng, one of the most commonly used and highly researched species of ginseng. This species, native to China, Korea, and Russia, has been an important herbal remedy for thousands of years in traditional Chinese medicine where it has been used primarily as a treatment for weakness and fatigue. It 
also boosts the immune system. Many products of ginseng are available in world markets for various disease conditions.

Cinchona, an anti-fever bark discovered by Europeans in the early 1500 s, was one of the medicinal plants to find appreciative consumers in Europe. Native peoples of the Andes and the Amazon used the bark of the Cinchona tree as an infusion to treat fever. Missionaries brought it to Europe. The quinine from the Cinchona tree was eventually isolated. Quinine is of course now well known for its anti-malarial use.

Similarly, the cocoa tree, Theobroma cacao, has excellent emollient properties and is used to soften and protect chapped hands and lips. Theobromine, the alkaloid contained in the beans, resembles caffeine in its action, but is less effective on the central nervous system. Its action on muscles, the kidneys and the heart is more pronounced. It is used principally for its diuretic effect due to stimulation of the renal epithelium. It is especially helpful against accumulation of fluid in the body resulting from cardiac failure, when it is often given with digitalis to relieve dilatation. It is also employed in cases of high blood pressure as it dilates the blood vessels. It is best administered in powders or cachets.

Dried rhizomes of Curcuma longa, turmeric, which give curry powder its characteristic yellow colour, are used extensively in foods to add flavour and colour. Turmeric has a long tradition of use in the Chinese and ayurvedic systems of medicine, particularly as an antiinflammatory agent and for the treatment of flatulence, jaundice, menstrual difficulties, hematuria, haemorrhage, and colic. Turmeric can also be applied topically in poultices to relieve pain and inflammation. Current research has focused on turmeric's antioxidant, hepato-protective, anti-inflammatory, anti-carcinogenic, and anti-microbial properties. In addition, it is used in treating cardiovascular disease and gastro-intestinal disorders.

The above examples indicate that multidimensional research on a single ingredient through a continuous process with various objectives could develop multiple applications. Ultimately, research has to lead to use by practitioners and benefit patients. 


\section{Is it acceptable to apply traditional medical and health practices within modern contexts?}

Abhyang, the ayurvedic massage, forms part of modern-day, healthclub regimes and Panchakarma, the ayurvedic therapies, are in demand as never before. Acupuncture is an accepted part of medical care all over the world. Yoga, too, has gone global in the right sense. The unparallelled richness of clinical and therapeutic information in ayurved needs to be explored and interpreted in the light of presentday advances in biomedical sciences. Research activities should contribute to the ability to improve knowledge and forms of practice in the medical field.

\section{What is the role of the modern education system in relation to ayurvedic research?}

The shift from guru shishya (the teacher-disciple system) to an institutionbased training structure gathered pace after Indian Independence in 1947, though the approach remained guru- or teacher-oriented. With the fast growth of conventional medicine and its increasing role and acceptance in other parts of the world, ayurved, a traditional medical system, struggled to exist in its country of origin. In its anxiety to survive and be modern, it adopted the model of teaching that was followed by the conventional system, more popularly known as allopathy. The individualistic learning of ayurved, which was based on the transmission of its skills and expertise through lineage and inheritance, took on the form of institutionalised and multi-faculty processes of teaching and training. With basic differences, such as ayurved's holistic cosmology versus allopathy's reductionist concepts, and a lack of integrative mechanisms, the transitional model has failed to provide the paradigm shift as envisaged.

During the British period, local rajas and philanthropists supported ayurved, with limited help from the government. Gujarat Ayurved University of Jamnagar is one such example. It started as the Gulabkunwarba Ayurved Society, and later became one of the first independent ayurvedic universities. Once recognised as part of education and training, the focus of research in ayurved has tended to follow the western medical model. Research along the lines of and parallel with modern medicine were pioneered and institutionalised at Banaras Hindu University. 
The sustained process of modernity clearly had both positive and negative consequences for ayurved. Several scholars, such as Jadavji Trikamji Acharya, Ranjitrai Desai, Ghanekar and Dwarakanath, to cite just a few, tried to integrate ayurvedic principles with the challenges of modernity in the context of medicine at different periods.

During the last 50 years, the institutionalisation of ayurved has developed into a unique situation unlike any other part of the world, with parallel existence of different but fully institutionalised, universityaffiliated and government-supported systems of medicine. The Central Council of Indian Medicine is governing education, training and the profession, and the Central Council for Research in Ayurved and Siddha is expected to lead research activities at national level.

\section{How is the training of ayurvedic doctors structured?}

The prevailing ayurved teaching and training course at national level lasts four and half years, followed by internship for the degree of BAMS (Bachelor of Ayurvedic Medicine and Surgery) or postgraduate degrees similar to $\mathrm{MD}$ and $\mathrm{PhD}$. The subject classification is the same as for allopathic courses; the syllabus is structured along the lines of the conventional medical or allopathic MBBS (Bachelor of Medicine and Bachelor of Surgery). The subject of anatomy has been termed 'sharir' and physiology 'kriya shareer', with ayurvedic components being incorporated into the classifications of conventional medicine subjects. This pattern has enriched multiple and specialised knowledge. It provides various other facilities like hospitals, laboratories and libraries. It has made ayurved more contemporary in all respects. However, despite having an infrastructure and facilities, the approach to research as part of education and as an instrument of serious inquiry and learning is missing. Today the focus of research at postgraduate level is on acquiring a degree by preparing a thesis or dissertation. The serious peer review system and orientation programme are totally lacking.

Research as a part of the curriculum should not be simply a mechanical procedure to evaluate information and knowledge but a dynamic process to evaluate developmental skills. It is necessary for research to evolve standardised methods and procedures, to coordinate and monitor review systems, and to accept open discussion to facilitate and share further advancement. More efforts are needed to improve research training, to understand the vagaries of nature, and 
to acknowledge personal limitations and unbiased views. Also to look positively at the experience of failure and success of thought as a learning process, rather than limiting the focus to the immediate output and outcome and thereby creating a restricted learning mindset and limiting environment.

\section{What are the consequences of new research methodologies applied in ayurvedic training and research?}

As a part of the ayurvedic education system, mainly at postgraduate level and also separately through independent, individual and institutional efforts, much research work has been carried out in ayurved. This has had both a positive and a negative effect. The following examples will give some idea about the research, which enriched the science but not so much the practice:

The interest in medicinal plants has taken different forms, such as pharmacognosy, ethnobotany, chemotaxonomy, and phytochemistry, and is currently driven by 'natural product chemistry'. Interest in ayurvedic medicinal plants goes back to the nineteenth century, and has found expression in extensive compendia on Indian medicinal plants, such as those by Kirtikar and Basu. Ayurvedic experts followed these early endeavours with informative and critical ayurvedic compilations, like Arya Bhishag, Vanaushadhi Chandrodaya, and later, Nighantoo Adarsh by Bapalal Vaidya, Dravya Guna Vignyan by P. V. Sharma and Gogate V. M. Many more incorporated these and even adapted them to the modern knowledge extant at the time. Currently several monographs on medicinal plants are laboriously prepared for publication by reputed institutes, and regular ayurvedic formulary and ayurvedic pharmacopoeia collated by the regulatory bodies are available.

Hundreds of research publications demonstrate the impact of ayurvedic plants or their fractions have on the body. While researchers have always sought to discover some unique cure in the plants being researched, the real benefit of the research has come by way of enhancing our understanding of the process of herbal research; 'reverse pharmacology' is a good example of this. Similarly, the pharmacological models, though highly inadequate to suit the needs of ayurvedic therapeutics, were applied to study the effects of plants and products. Consequently, after several years of experience and experimentation, 
an altogether different product development process with newer approaches to standardisation and evidence is emerging.

Drug development has always been driven by the modern methodology of testing specific synthetic chemical drugs, to prove efficacy, safety, and meet the requirements of standardisation. This has not always helped. It is difficult to satisfy requirement guidelines and parameters of modern drug research for ayurvedic products. Phased studies for development of a new chemical entity as a drug cannot be applied here. Compromised clinical studies do not stand to the test of scientific query and double-blind controlled clinical trials disrupt the scope of holistic evaluation of safety and efficacy of ayurvedic drugs. An ayurvedic remedy is prescribed for an ailment in cognisance of a range of host factors, which are ignored in such trials. In the end, the results of studies that are incompatible with the ayurvedic paradigm remain unacceptable and inconclusive or are perceived as negative. With very few exceptions, the data on these clinical studies and validation theories of ayurvedic formulations or treatments are incomplete and reflect poorly on ayurved. Though evidence-based studies are considered and undertaken, there still exists an urgent need to develop appropriate research models for clinical research in ayurved.

The ayurvedic treatment for Amavata and Sandhigatvaat, considered similar to rheumatoid arthritis and osteoarthritis respectively, have been found effective and have been widely accepted. During the past 35 to 40 years, a large number of clinical studies have been carried out throughout the country. However, with the failure to incorporate ayurvedic principles into basic hypothesis construction and to focus on variables aligned to ayurvedic understanding, effective treatment guidelines are still missing. If well-researched treatment suggestions and guidelines were available, they would be of great help to practitioners of ayurved, alleviate the suffering of patients, and unquestionably bring wider recognition to the system.

Similarly, I-dopamine contained in the plant Mucuna pruriens, has been developed for treatment of Parkinson's disease with international standards of validation and safety. However, as the dose requirement of the powder is very high $(70 \mathrm{gm})$, it has not been favoured. L-dopamine is known to be unstable in water and binds to fat; in ayurved the plant is used in ghee or other oily or fatty substances only. Consideration of ayurvedic usage might have helped easier application and better treatment compliance. The science was enriched 
by research into I-dopamine in Mucuna pruriens, but conversion to day-to-day application was limited.

Research has shown the efficacy of ayurvedic substances by the standards of conventional medicine, but application in terms of newer interpretations is rare. Science may have been enriched by means of all kinds of research, but its use to the ayurvedic profession has been limited. No standardised product for particular kinds of condition is being developed, which could be utilised by all professionals. The progress of ayurved has lately been driven by modern scientific requirements and consumer demand. In this era of segmentation, ayurved is on the verge of losing its roots and is being driven towards herbalism. Efforts to provide a comprehensive approach are sporadic. Clinical expertise and observational knowledge are declining. This will be a great loss to ayurvedic science and practice in general.

\section{Has textual analysis any place in modern ayurvedic research?}

Literary research has become a highly neglected area of research in ayurved in India. Over the last three decades, parallel to the national institutionalisation of teaching, literary research has taken a backseat. The study and transcription of ancient manuscripts is rarely undertaken. Whereas there are many new textbooks to satisfy the curriculum (and of varied quality), serious literary research and innovative approaches to the interpretation of original texts are limited. At the same time, the interest and works of western scholars on ayurvedic literature is fascinating and encouraging.

\section{How could the profile of existing cutting-edge ayurvedic research efforts be improved?}

The documentation of research endeavours and results is currently poor, not least due to a lack of awareness as to how to go about data generation and documentation, but also because of a lack of confidence on the part of investigators to face scientific scrutiny. Despite a large number of Indian institutes for training and research, the acceptance of research publications in international journals remains paltry. Some excellent work has been done, yet sometimes 
it is viewed with mistrust and concern. It is important to improve this situation and to develop ways of facilitating data generation and documentation in ayurvedic institutes in India, and to encourage the wider - also international-dissemination, reception and discussion of ayurvedic research. There are some journals, supported by private corporations, with their own ethos and interests, but there is not a single Indian journal that meets stringent international standards of quality assurance and peer review.

It is very important to keep in mind that ayurved is not confined to medicine only. It deals with life and living as a whole. The outcome of research should help to establish meaningful correlations between ayurvedic concepts and modern scientific discoveries that are relevant and useful to people living in a modern world. However, ayurvedic aspects remain poorly incorporated in research, as basic principles are not adequately understood or interpreted. This is also due to the lack of modern tools to examine the correlation between a process-focused system and the bio-medical system. As a result, most of these efforts remain limited or unproductive. This constitutes a challenge to the modern ayurvedic researcher.

\section{Are you pessimistic?}

No. In fact I am highly optimistic about the significance of ayurved and its principles in future medicine. My concerns are about its ayurvedic identity, future form and Indian initiative to lead and deliver. 